\title{
Haqua Diet Therapy (HDT): A New Approach to your Holistic Health
}

\author{
Faris Al Hajri* \\ Haqua Revitalize ${ }^{\circledR}$ Therapy, President and CEO of Haqua Wellness, Virginia \\ *Corresponding Author: Faris Al Hajri, Haqua Revitalize ${ }^{\circledR}$ Therapy, President and CEO of Haqua Wellness, Virginia.
}

Received: October 11, 2019; Published: November 27, 2019

DOI: $10.31080 /$ ASNE.2019.02.0127

\begin{abstract}
Diet has been an issue of various scientific debates and controversies. Various scientific studies have been conducted to prove the effectiveness of a specific recommended diet, but, later, it resulted to various controversies, with time passing, due to various factors; such as counting the numbers of calorie consumed versus to that the body can expand daily; the low-carbohydrate diet, the GAPs Diet, the Paleo Diet, the Atkins Diet, or following a specific nutritional diet; etc.
\end{abstract}

Keywords: Diet; HDT; IIN; Haqua Revitalize ${ }^{\circledR}$

During my Health Coach Training Program with the Institute for Integrative Nutrition (IIN), in New York; the world's largest nutrition school, various topics of diets were introduced by renowned researchers; where rooms were opened to acquire various controversies in regard to diet. IIN concluded with some of its core concepts that embody the important theories and ideas that IIN was founded on, among these, is the concept that no one diet or lifestyle works for everyone. People have their own unique needs and will have a way of eating and living that works best for them. Your perfect diet could make someone else gain weight or feel lethargic, while someone else's morning run could leave your body feeling weak and depleted.

In our extensive studies we conducted so far, we concluded that our body resembles to a vehicle, that it needs regular maintenance, and maintaining its fuels to keep it running at its full performance. If one of the vehicle fuels deplete; engine oil, break oil, transmission oil, power steering oil, coolant, etc; then the vehicle will not run at all. Regular maintenance keeps the vehicle to run effectively as well. Similar principle applies to the human body. But the difference is that a vehicle is a man-made machine, thus it relies on its artificial man-made fuels. Whereas, the human body, is not a man-made machine, it relies on its exclusive natural fuels, to maintain its innate ability to self-healing, self-regulation, and self-maintenance. Anything that is taken inside our bodies, poses a threat more that it may pose a benefit, if it lacks any of its essential natural fuels. So on with the food we eat, may pose a threat, if our bodies do not maintain the minimum required amount of its fuels. We coined these fuels, as the Four Essential Elements of Life (FEEL's).

"Haqua" derives from two words "hot", and "aqua" from the Latin word "water". Thus hot aqua simply means hot water. Revitalize represents the reinstatement of the human's body to its initial state of creation in the precise form of complete PEMS (Physical, Emotional, Mental, and Spiritual) health.

As we enter the twenty-first century, our planet becomes increasingly modernized. The evolution of technology, the digital revolution, telecommunication, high power electric lines and equipment, wireless electronic devices-all these factors contribute to a fast-paced, on-demand lifestyle. Perhaps they allow for more human comfort. However, climate change and eco-destruction caused by pollution, toxic substances from chemicals, factories, fast food, preservatives, etc., have detrimentally affected human health, resulting in various diseases, such as, diabetes mellitus, high blood cholesterol, cancer, obesity, etc. 
Increasing scientific findings on the subject have proven the importance of proper food nutrition. Green vegetables and fruits consumption enhance food metabolism and physical exercise aids in burning fats. Unfortunately, it can be difficult for many to maintain a strict dieting program because their body craves high-calorie food. Athletes and others maintaining extensive physical exercise often struggle late in life with health complications like arthritis, osteoarthritis, rheumatisms, and other bone-related health issues. These health struggles occur when the body is depleted of the Four Essential Elements of Life (FEEL's). A proper diet and moderate exercise are essential to good health, but Haqua Revitalize ${ }^{\circledR}$ Therapy (HART) is the primary key to achieving a comprehensive, healthy lifestyle.

In this chapter, we will reveal and discuss the hidden mysteries of Haqua Revitalize ${ }^{\circledR}$ Therapy (HART) that will remove various controversies on food nutrition and exercise. Haqua Diet Therapy (HDT), one of the modalities of Haqua Revitalize ${ }^{\circledR}$ Therapy (HART), is the most vital factor for losing weight and maintaining proper body fitness.

Food preservatives cause detrimental side effects to human health, but it is often almost impossible to obtain fresh, preservative-free food in a timely manner. The Haqua Revitalize ${ }^{\circledR}$ Therapy (HART), as well as the modalities offered here, not only aids in general and specific health, it eliminates the toxic substances that the body has accumulated from the food we all eat. This therapy has the power to change our lives and that of our future generations, and we will continue to live in comfortable lifestyles, with better health and well-being.

\section{Personal hypotheses and scientific facts}

Haqua Revitalize ${ }^{\circledR}$ Therapy (HART) is categorized into various modalities and two specifically address weight loss and maintaining a holistic health lifestyle: Therapeutic Methods of Haqua Gulping (TMHG) and Haqua Diet Therapy (HDT). Haqua Diet Therapy (HDT) lowers the daily food intake by $50-70 \%$, even up to $90 \%$, by allowing the body to absorb natural, clean energy through 'haquation'.

Since the human body obtains most of its energy from the food that is daily consumed, eating less can lower the metabolic rate as the body tries to preserve energy. The hypothesis behind this new diet therapy, however, solves the above-mentioned difficul- ty. Haqua transfers energy to the body through 'haquation', lowering the body's need to obtain energy from food metabolism. The word 'hydration' simply means making the body absorbing water or liquid. Whereas 'haquation' means making the body absorbing 'haqua', otherwise known as 'hot aqua', or 'hot water'.

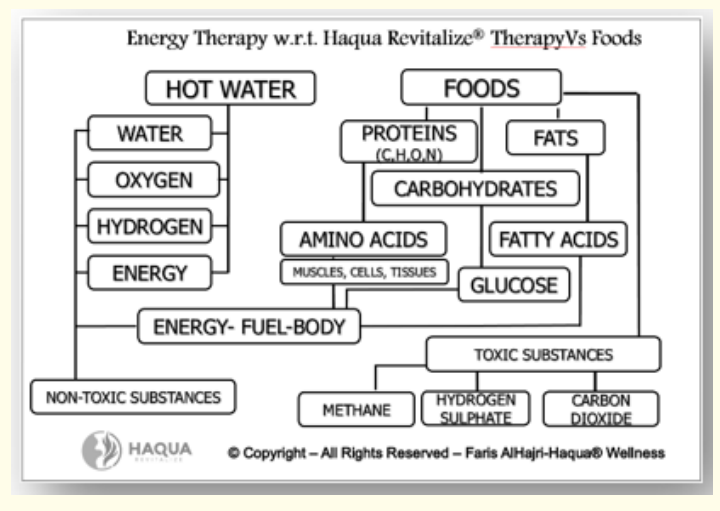

Figure 1

It is recommended, therefore, that the daily volume of food eaten is lowered upon implement the Therapeutic Methods of Haqua Gulping (TMHG) and the Haqua Diet Therapy (HDT).

Unlike drugs that are taken to raise the metabolic rate artificially, Haqua Revitalize ${ }^{\circledR}$ Therapy (HART) has a strong, positive impact on our health, even apart from reducing the global food-shortage and eradicating poverty.

The diagram above shows that Haqua Revitalize ${ }^{\circledR}$ Therapy (HART) allows the body to absorb the amount of energy it needs without toxic leftovers. Methane (CH4), hydrogen sulfide (H2S), and carbon dioxide ( $\mathrm{CO} 2$ ) are formed through the metabolic process needed to change food into energy. These toxic substances endanger not only our physical health, but also our mental, emotional, and spiritual well-being.

Food metabolism

The process of food metabolism-all the physical and chemical processes in the body that convert or use energy-is an efficient chain of events, that, in a healthy human being, allows to body properly utilize all food that is eaten. The energy obtained from this process powers everything mankind does, from growing and mo- 
ving to thinking. After food is eaten, enzymes-complex proteins that cause a specific chemical change in all parts of the body-in the digestive system break protein down into amino acids, fat into fatty acids, and carbohydrates into glucose. All three substances are employed as energy sources by the body as needed.

Absorbed into the blood, these compounds are transported to the body's cells where other enzymes increase and regulate the chemical reactions involved with "metabolizing" these compounds. During these processes, the energy from these compounds can be released for the body's use or stored in body tissue, especially liver, muscles, and body fat.

In an article published by Mayo Clinic in finding a relationship between metabolism and calorie burning, and how metabolism affects weight, the truth behind slow metabolism and how to burn more calories; it highlighted the definition of metabolism as the process by which your body converts what you eat and drink into energy. During this complex biochemical process, calories in food and beverages are combined with oxygen to release the energy your body needs to function. Even when you're at rest, your body needs energy for all its "hidden" functions, such as breathing, circulating blood, adjusting hormone levels, and growing and repairing cells. The number of calories your body uses to carry out these basic functions is known as your basal metabolic rate - what you might call metabolism [1].

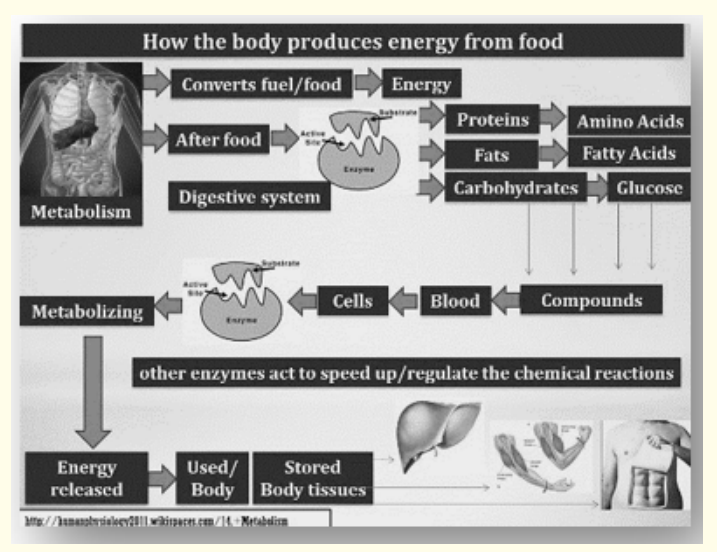

Figure 2

Well, calorie is directly linked to Haqua Revitalize ${ }^{\circledR}$, specifically, to the relationship between water and energy (heat). Scientifically, a calorie is defined as the amount of heat required to raise the tem- perature of one gram of water from 14.5 degrees Celsius to 15.5 degrees Celsius. Heat always refers to the transfer of energy between systems (or bodies), not to energy contained within the systems (or bodies). As a form of energy, the SI unit for heat is the joule (J), though heat is frequently also measured in the calorie (cal), which is defined as Heat is also sometimes measured in "British thermal units" or Btu. Calorie is also known as thermal energy [2].

There are two types of metabolic reactions take place in the cell: 'building up' (anabolism) and 'breaking down' (catabolism). Anabolic reactions use up energy. They are endergonic. In an anabolic reaction small molecules join to make larger ones. Catabolic reactions give out energy. They are exergonic. In a catabolic reaction large molecules are broken down into smaller ones [3].

The organs of the excretory system help to release wastes from the body; the lungs remove carbon dioxide; the skin release sweat glands remove water, salts, and other wastes; the large intestine removes solid waste and some water in the form of feces, and the kidneys remove urea, salts, and excess water from the blood [4].

The excretory systems remove metabolic wastes, such as carbon dioxide $\left(\mathrm{CO}_{2}\right)$, methane $\left(\mathrm{CH}_{4}\right)$, nitrogen compounds $(\mathrm{N})$, phosphates, and hydrogen sulfide $\left(\mathrm{H}_{2} \mathrm{~S}\right)$, can lead to major allergies, infections, and diseases, unless frequently excreted from the body. The longer these metabolic wastes stay inside the body, the more they infect its organs. Those who suffer from constipation face a higher risk of health complications since they do not drink enough water.

The metabolic system produces heat, which is then released as energy. The hot water implemented in the modalities of Haqua Revitalize $^{\circledR}$ Therapy (HART) not only offers the needed heat, but also would relieve the body of waste from the original metabolic process. These therapies alone offer all the elements that the body needs without harmful waste substances. Healthy nutrition is also highly recommended, but, for those who are not able to change their nutrition habits, cutting down on the food intake and substituting to this therapy will allow them to live a healthy lifestyle without losing the energy their bodies need to survive.

Food metabolism

1. Naturally reduces the amount of metabolic wastes.

2. Enhances the enzymes to easily breaking down more calories, even without any physical activity. 
3. Substitutes most of the energy obtained from foods with Haqua (hot water).

4. Helps reducing the amount of daily food intake by volume between $50-70 \%$ and up to $90 \%$. Consequently, toxic substances from food metabolism-carbon dioxide $\left(\mathrm{CO}_{2}\right)$, methane $\left(\mathrm{CH}_{4}\right)$, nitrogen compounds $(\mathrm{N})$, phosphates and hydrogen sulfide $\left(\mathrm{H}_{2} \mathrm{~S}\right)$-are dramatically reduced.

5. Reduces the need for enzyme-fueled energy for the cells, as energy is effortlessly supplied through Haqua Revitalize ${ }^{\circledR}$ Therapy (HART).

6. Enhances the body to maintain the amount of its natural body's essential fuels.

7. Helps losing weight naturally and effortlessly.

8. Prevents degenerative ailments that result from obesity and that occur in the arteries and kidneys, as well as hypertension and cardiovascular disease.

9. Helps the body to maintain a consistent internal temperature which encourages healthy bodily functions.

10. Increases the body's weight for those who are underweight, by increasing bone density.

Substituting food with haqua

- $\quad$ Avoid diet foods from which protein and other minerals have been extracted.

- Avoid fast foods on daily basis, except once or twice weekly.

- $\quad$ Avoid the consumption of fried foods. In some exceptional cases, where fried foods are your only available meal, steam the food before eating. This way, the oil deposits will be reduced by the steam. Grilling is also a possibility.

- Have some healthy dry foods to eat every three hours in lower quantity. This suppresses your appetite.

- $\quad$ Always make sure to Haquate your body (hydrate your body with a glass of hot water) through the gulping method, at least 15-30 minutes before meal.

- Avoid going three hours without Haquating your body.

- $\quad$ Avoid gulping more than one liter (34 oz.) or 2 big glasses, tumbler or mug of $500 \mathrm{ml}$ (17 oz.) of Haqua within an hour.

- Avoid heavy meals except once or twice weekly.

- It is always healthy to consume a very small amount of food when you are hungry. Do not feel like you need to abide by any set time.
- Enjoy your daily favorite coffee, tea, or warm fresh juice and mostly avoid drinking very cold drinks.

- $\quad$ Focus on getting your nutrition from what you eat. A small portion of fresh fruits, vegetables, meat, poultry, and fish should be enough to satisfy your body's need for the vitamins and proteins.

- Exercise regularly and on daily basis at least twenty minutes' walk constantly. Daily moderate exercise is better than intensive exercise.

Methodology

The methodology of Haqua Diet Therapy (HDT) is to fully implement the Therapeutic Method of Haqua Gulping (TMHG) on a daily basis, at the specific temperature for adults and that for children, with the specific methodology, and timings.

Gulping Method, also coined as Therapeutic Method of Haqua Gulping (TMHG).

For adults

- The daily recommended consumption of Haqua (Hot Water) is a minimum of 3 liters $(101 \mathrm{oz})$ and maximum of 4 liters (135 oz).

- $\quad$ The water volume taken should not exceed $500 \mathrm{ml}(17 \mathrm{oz})$ at one time, and a maximum of 1 liter ( $34 \mathrm{oz}$ ) in the span of an hour.

- Shall abide with the recommended temperature of Haqua, fixed at around $50^{\circ} \mathrm{C}\left(122^{\circ} \mathrm{F}\right)$, a little bit less than the temperature of hot tea or hot coffee.

- There are three ways to ingest water or another liquid by the mouth: drinking, sipping, or gulping. This therapy requires the subject to gulp Haqua (hot water), instead of drinking or sipping it.

- A glass of Haqua should be slowly gulped in mouthfuls without stopping. The intervals between gulps should be around 5-10 seconds.

- A whole tumbler of size of $500 \mathrm{ml}(17 \mathrm{oz})$ is highly recommended every 2-3 hours.

- Good quality tumblers are usually made up of high insulated materials that may maintain the heat between 6-12 hours. It is highly recommended the inner coating of the tumbler or mug to be made of Stainless Steel. 
- It takes around 1-2 minutes to gulp a whole $500 \mathrm{ml}(17 \mathrm{Oz})$ glass, tumbler, or mug of Haqua taken between 9-15 gulps at temperature around $50^{\circ} \mathrm{C}\left(122^{\circ} \mathrm{F}\right)$.

- Do not exceed more than a 3 hour-interval, except in urgent and exceptional cases.

- It is strongly recommended that mixing your Haqua (hot water) with any additives is to be avoided. Any change of water's temperature, or addition of additives, immediately alters its molecular state, and it can even become toxic, or harmful.

- $\quad$ Because the body will rid itself of toxins, there may be a few unpleasant effects. This, however, is a natural result and a healthy response to Haqua's cleansing work. The detoxification process includes excreting metabolic wastes, accumulated toxins, harmful bacteria and excess fat deposits (lipids).

- There may be some irregular stomach discharge, frequent urination and sweating. This symptom usually lasts for a week or two (more or less) before the body gets revitalized back to its normal condition.

- $\quad$ Some vomiting is possible and may continue for 1-2 times while the body detoxes.

- A specific Therapeutic Methods of Haqua Gulping (TMHG) for children and babies has been formulated, in terms of temperature, quantity and methods.

- $\quad$ The following Haqua Common Gulping Method (HCGM) is one of the various modalities of the Therapeutic Methods of Haqua Gulping, depending on schedule tailored to suit the beneficiary, the water temperature and program. that suit babies, toddlers, and children.

Haqua Common Gulping Method (HCGM) [glass size $500 \mathrm{ml}$ (17 oz)] - For adults

1. One glass upon waking and on a 'clean' mouth - at a standing position.

2. One glass between 7:00-10:00 a.m.

3. One glass 15-30 minutes before lunch.

4. One glass between 2:00-4:00 p.m.

5. One glass in the evening, 15-30 minutes before dinner.

6. One glass an hour before sleep.

\section{Conclusion}

Diet has been an issue of various scientific debates and controversies. Various scientific studies have been conducted to prove the effectiveness of a specific recommended diet, but, later, it resulted to various controversies, with time passing, due to various factors.

The human body relies on its essential natural fuels. We coined them, the Four Essential Elements of Life (FEEL's). In our extensive hypotheses we conducted for the past twelve years, we found these body's essential fuels could be the ultimate solution to resolve the various controversies in diet. They are found to be the key towards metabolizing the foods you eat to produce the energy your body needs in order to breathe, circulate blood, built the muscles, grow and repair cells, and everything else it does to survive. In addition, these fuels are essential in the process of excreting the toxic substances resulted from the metabolic wastes. The volume of the food you eat should be minimized, and substituted to Haqua (hot water), leaving the body to rely the energy it requires from Haqua would be much safer than that it relies from the foods you eat.

\section{Bibliography}

1. Metabolism and weight loss: How you burn calories.

2. Heat Energy - Definition and Examples. about education.

3. Metabolism and energy. Royal Society of Chemistry.

4. Excretory System.

\section{Volume 2 Issue 12 December 2019 (c) All rights are reserved by Faris Al Hajri.}

